\title{
Seepage Cut-off Wall Detection of Reservoir Based on Groundvue Series of Ground Penetrating Radar
}

\author{
YUAN Baoyuan ${ }^{1, a^{*}}$, LI Yongjun ${ }^{1, b}$ and BAI Yun ${ }^{2, c}$ \\ ${ }^{1}$ College of Earth Science and Engineering, Hohai University, Nanjing, China \\ ${ }^{2}$ Water Conservancy and Hydropower Survey and Design Institute of Qinghai, Xining, China \\ aybylih@vip.sina.com, b878190058@qq.coml, qhslby219715@163.com
}

Keywords: Ground Penetrating Radar, Groundvue series, Nanmenxia Reservoir, seepage cut-off wall, detection

Abstract. In order to find out the serious and long plagued leakage problems related to the seepage cut-off wall of Nanmenxia Reservoir, used the introduced British Groundvue series of Ground Penetrating Radar equipment, field test and verify work were implied, leakage location and path were determined. The results showed that the seepage cut-off wall of dam foundation is well, its thickness is around $0.50 \mathrm{~m}$, but it has the horizontal distance of about $3 \mathrm{~m}$ away from the current grouting platform, which may be one important cause that the previous grouting effects are bad. This provided important support for the Reinforcement Project of Nanmenxia Reservoir.

\section{Introduction}

Nanmenxi reservoir is a medium-sized project mainly used for irrigation. It was founded in 1974 and put into operation in 1982. Because the reservoir is located in karts areas, it have complex geological conditions, and leakage is also serious. Nanmenxia reservoir seepage treatment work has already begun as early as 1975. It has been carried out three stages of curtain grouting, but the effect was not ideal. The dam of Nanmenxia Reservoirs were identified more serious dangerous on the safety appraisal in October 2010, including the leakage of dam (shoulder) seriously, seepage stability. It affected the safety of flood discharge. The reservoir can't normal operation according to the requirements of design. It is a third class dam. To maximize the social and economic benefits of the reservoir and prevent major disasters, the reinforcement of the reservoir will be carried out recently approved by the Ministry of Water Resources.

British Utsi Electronice company's Groundvue series of Ground Penetrating Radar test system has the world's lowest frequency of a radar. It can detect the deepest 180 meters and trigger a GPS measurement. It has fast work efficiency. Introduction of GPR equipment and technology, combined with on-site testing and validation, to understand the situation of seepage cut-off wall of Nanmenxia Reservoir's dam foundation, which can provide technical support for the reinforcement construction.

\section{Groundvue series of ground penetrating radar system}

Groundvue series of ground penetrating radar test system's main technical indicators: scan rate of four-channel radar host is 250 sweep / sec; $400 \mathrm{MHz}$ antenna frequency range: 200-600 MHz; 50 MHz Antenna Frequency range: $30-100 \mathrm{MHz} ; 15 \mathrm{MHz}$ Antenna Frequency range: $5 \mathrm{MHz}-30 \mathrm{MHz}$; high pulse repetition rate: $2 \mathrm{M} \mathrm{Hz}$ to $500 \mathrm{KHz}$.

Geological radar antenna according to the classification in different ways can be classified into different types of antennas. From the nature of the work, it can be classified into transmit and receive antennas; from the shield or not shield, it can be classified into shielded and unshielded antenna ,as shown in figure 1.

\section{On-site test}

The main survey line is arranged in the top and fore slope of the dam. The main detecting route include: three equidistant longitudinal survey lines along the highway direction on the dam crest, two longitudinal survey lines on the dam fore slope grouting platform, they were GV2 and GV6 detection; 
Dam fore slope survey lines were detected from grouting platform to the top of slope. It's direction perpendicular to the dam's trend. Because there are many stone on dam slope, it was not conducive to lager size and weight GV2's probe (smaller effect on the light GV6), so the measuring space was arranged to $3.5 \mathrm{~m}$. The total of survey lines is 26 . Test method is shown in figure 2 .
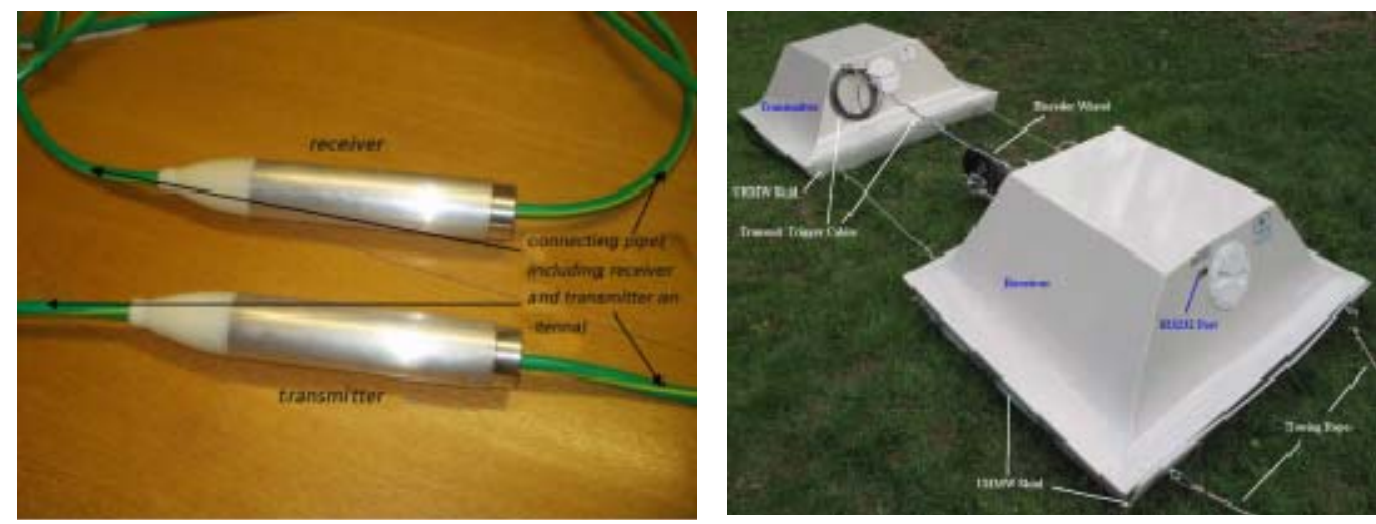

Figure 1 GV series of ground penetrating radar antenna
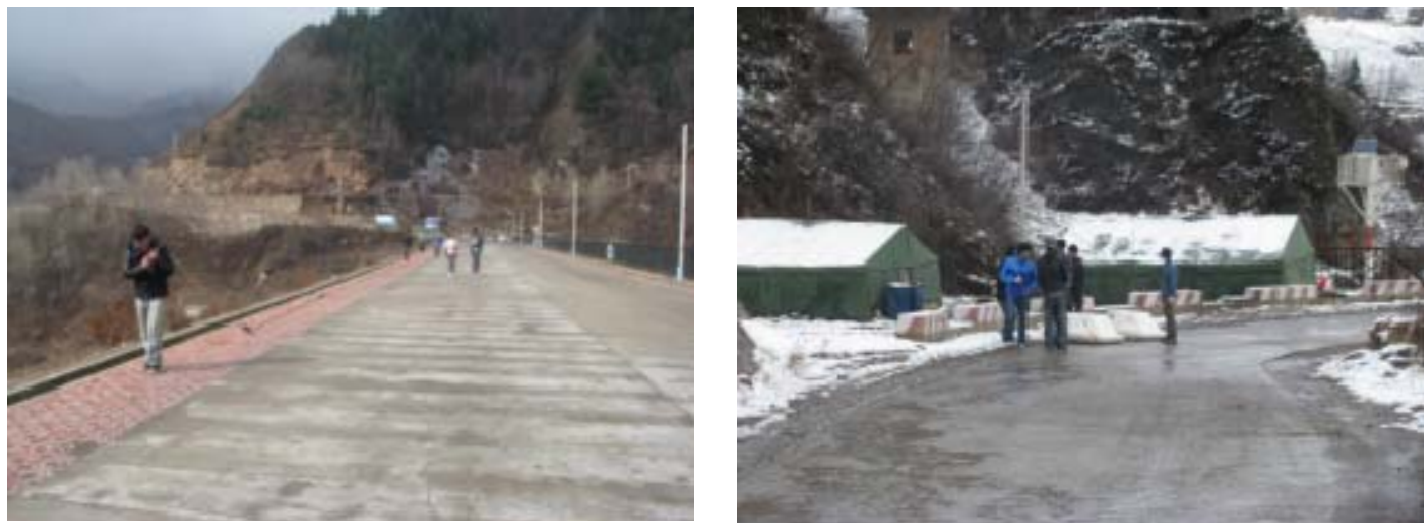

Figure 2 GV6, GV2 measured at the crest of the dam

\section{Indoor test}

For a reasonable analysis of Nanmenxia reservoir's images measured by GV ground penetrating radar, Hohai University established a simulation platform based on $1 \mathrm{GHz}$ of GV3 ground penetrating radar antenna in the laboratory, to understand the characteristics of the target model image measured by GV ground penetrating radar. As shown in Figure 3.

\section{Interpretation and validation of test data of the cut-off wall}

Concrete cut-off wall of the dam foundation is located in dam fore slope between the base surface and the bedrock surface and used to prevent gravel overburden on the bedrock surface seep. Due to the lack of accurate drawings of the original design, during the previous dam foundation grouting, it is generally believed that the cut-off wall is on the edge of the existing grouting platform and parallel with the strike of the dam.

Used GV6 GPR to test in dam fore slope. The direction of survey line is perpendicular to the dam trend and from the bottom of the slope to the dam crest. The measuring grayscale image of the $0+034$ section see image 4. From the image, we found there are some reactions of GPR electromagnetic waves in dam fore slope, whose position is $26 \mathrm{~m}$ away from the dam crest and at a depth of $26 \mathrm{~m}$ and $32 \mathrm{~m}$. So we suspected it is the location of concrete cut-off wall. The location is parallel with the strike of the dam, near the grouting platform toward to the dam crest, 3m away from the existing grout platform. This may be an important reason of previous poor grouting effect. 


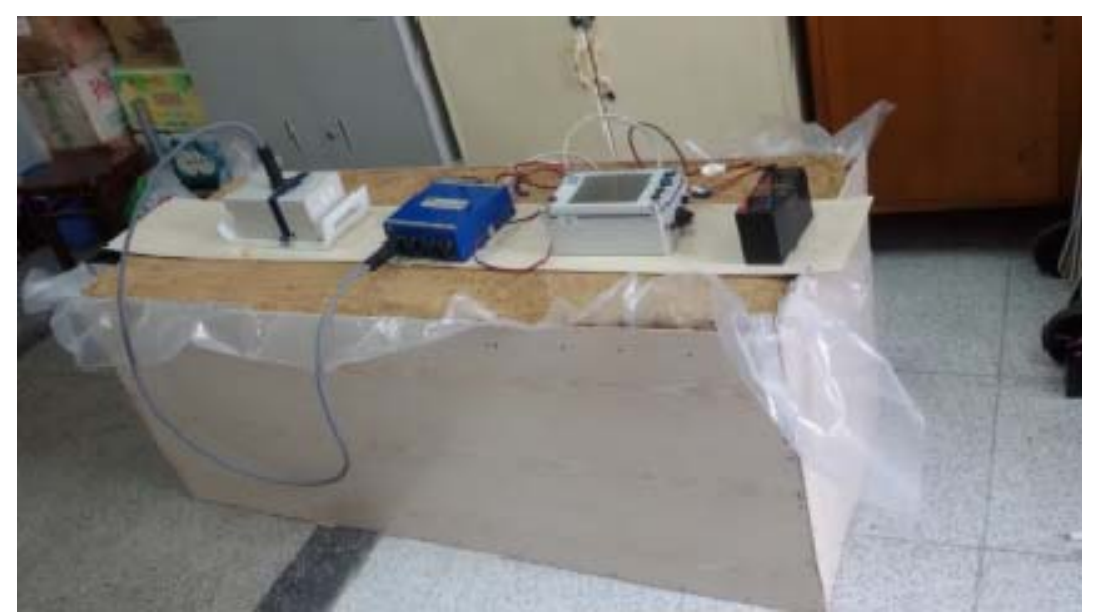

Figure 3 GV ground penetrating radar indoor test platform

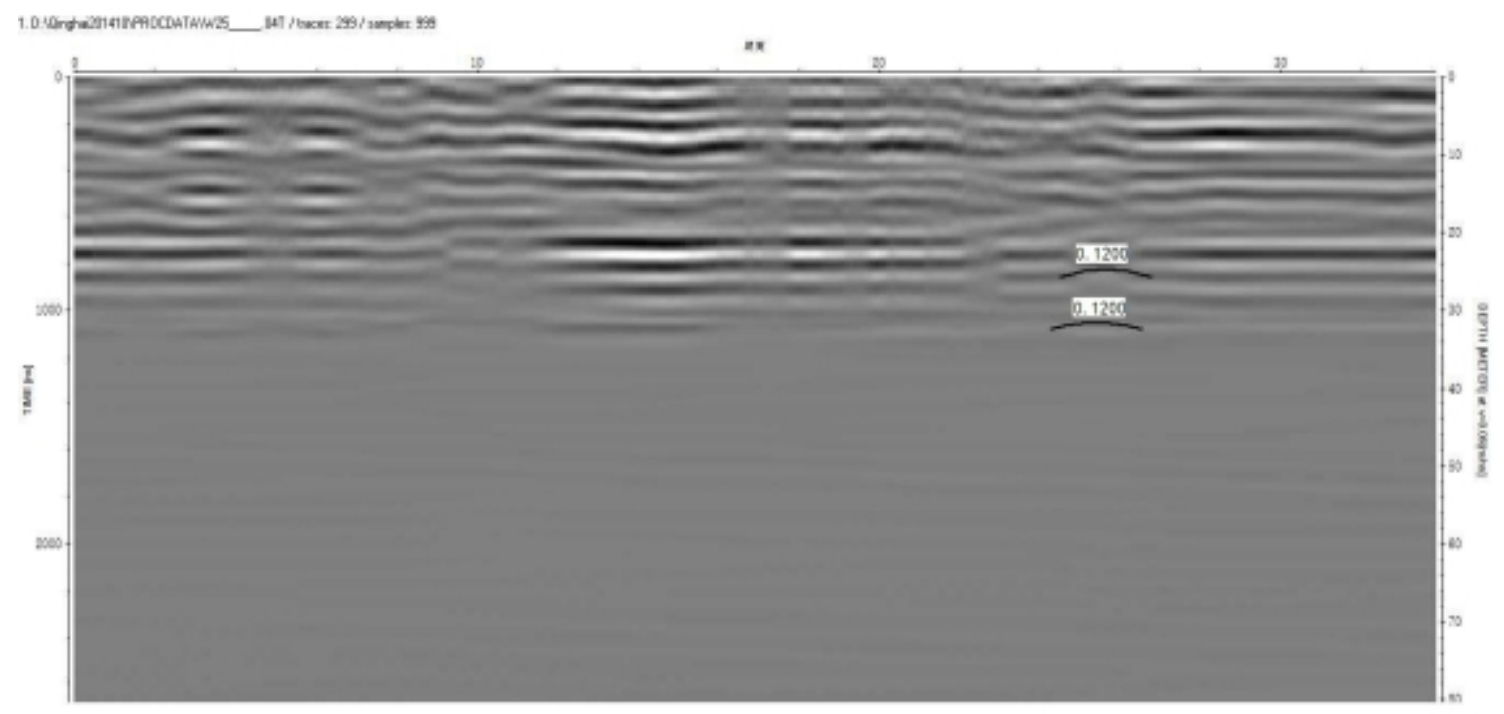

Figure 4 GV6 grayscale image of $0+034$ section in dam foreslope vertical to the dam axis

In order to confirm the above speculation, we view the radar images of other positions that are parallel with that survey line. We found most of the GPR images that are parallel with the $0+034$ section appear suspected GPR reactions almost at the same position. In Figure 5 we can see the GPR arc of $0+208$ section, whose position is in the dam fore slope $24 \mathrm{~m}$ away from the dam crest, at a depth of $24 \mathrm{~m}$ and $32 \mathrm{~m}$.

From the relative positions of the two reflex arcs in Figure 4, the shallower reflex arc is often closer to the left than the deeper reflex arc. This is not difficult to explain. Because the measurement is carried out from bottom to top, and there are a 20 degrees slope toe between the measurement path and the horizontal. With respect to the vertical concrete cut-off wall there is an angle of 70 degrees. When the measuring route is displayed in the image in the horizontal direction, the cut-off wall in the image naturally shows a tilt angle of 20 degrees relative to the vertical direction. Form a "tilt wall" phenomenon.

Through observation and analysis of 26 GPR images that are perpendicular to the dam strike and parallel with each other, we can discover the location of concrete cut-off wall in the dam foundation that is along the slope and $11 \mathrm{~m}$ away from the dam crest, about $3 \mathrm{~m}$ away from the existing grout platform. The distance from the surface to the top of the cut-off wall rang from 26 meters to 30 meters, so it is likely that the top of cut-off wall is not on the same elevation. And cut-off wall between the 0 $+40 \sim 0+380 \mathrm{~m}$ monolith continue good.

In order to confirm the results of the above interpretation of GPR detection, we use on-site drilling to verify. According to the results of GPR test analysis, we lay out the location of first drilling on site. First, we arranged a borehole ZK14-1-1 on the location of stake number $0+383.60 \mathrm{~m}$ in the right dam 
abutment, which exposes the artificial accumulation of soil and then hit the sand and gravel, but we did not find the concrete cut-off wall at $25.0 \mathrm{~m}$ deep. After analysis, we moved $0.70 \mathrm{~m}$ toward downstream, arranged the boreholes ZK14-l-2 and found concrete cut-off wall at 25.0m deep. Then, we arranged a borehole ZK14-3 on the place of stake number $0+383.60 \mathrm{~m}$, found the cut-off wall at 28.50m. After that we arranged a borehole ZKl4-4-1 in the place stake number $0+150 \mathrm{~m}$, not find the cut-off wall. And then we moved $0.60 \mathrm{~m}$ toward downstream, arranged a borehole ZK14-4-2 and found concrete cut-off wall at $31.0 \mathrm{~m}$ deep.

The cut-off wall is not on a top elevation. At the place of stake number $0+034.2 \mathrm{~m}$, the top elevation of the cut-off wall is $2736.45 \mathrm{~m}$, bottom elevation is $2721.05 \mathrm{~m}$, wall height is $15.4 \mathrm{~m}$. The main drill results see Table 2 . Drilling verification about the cut-off wall explained the original cut-off wall is in a straight line. The cut-off wall is spreading from the centerline curtain grouting of upstream horse way in 2012 to downstream. On the left bank it spreads $5.4 \mathrm{~m}$, and on the right bank it spreads $6.1 \mathrm{~m}$.

\section{Conclusions}

For a long time, the seepage problem of Nanmenxia Reservoir has not been able to solve better, and the utility problem of anti-seepage wall may be a key problem, so, the important support is provided for the solution to the key problem by introducing British Groundvue geological radar equipment and software.

According to the comprehensive analysis of multi-way measuring line of the front slope of dam that GV6 locates, the position of the anti-seepage wall for geological radar test analysis of concrete anti-seepage wall is $5.4 \mathrm{~m}$ from the center line of upstream pack way curtain grouting to downstream left bank and $6.1 \mathrm{~m}$ away from the right bank, the thickness of the anti-seepage wall is about $0.50 \mathrm{~m}$, and it has the horizontal distance of about $3 \mathrm{~m}$ away from the current grouting platform, which may be one important cause that the previous grouting effects are bad.

As the indoor test platform of GV3-1G antenna is able to effectively simulate and test the radar image characteristics of underground target objects, its results help to improve the detection interpretation efficiency of Groundvue geological radar.

\section{Acknowledgements}

This work was financially supported by the 948 Foundation of the Ministry of Water Resources (201325)

\section{References}

[1] Chen Yiqun, On the status quo and development of ground penetrating radar, J. Chinese Journal of Engineering Geophysics .16(2005)51-55.

[2] Ma Huijie. The karsts and seepage treatment of Nanmenxia Reservoir, J. Hydrogeology and Engineering Geology. 21(2002)43-48.

[3] LI Y, CHEN J J C. Ground penetrating radar signal processing improves mapping accuracy of underground voids and seawater table: an application in deteriorating coastal structure, Nanfangao Port, Taiwan, J. Enviro- nmental Geology, 43(2007)35-39. 